\title{
Study on Dynamic Constitutive Model of Weakly Consolidated Soft Rock in Western China
}

\author{
Lei Wang, Hongming Su $(\mathbb{D}$, Yue Qin, and Shiguan Chen \\ College of Architecture and Civil Engineering, Xi'an University of Science and Technology, Xi'an, Shaanxi 710054, China \\ Correspondence should be addressed to Hongming Su; 993765278@qq.com
}

Received 25 June 2020; Revised 25 July 2020; Accepted 6 August 2020; Published 28 August 2020

Academic Editor: Qing Ma

Copyright (C 2020 Lei Wang et al. This is an open access article distributed under the Creative Commons Attribution License, which permits unrestricted use, distribution, and reproduction in any medium, provided the original work is properly cited.

\begin{abstract}
To obtain the impact mechanical response and establish the dynamic damage constitutive relationship of frozen sandstone at low temperature conditions, the impact test of Cretaceous red sandstone under different temperatures was conducted using a split Hopkinson pressure bar (SHPB) device. According to the characteristics of the stress-strain curves obtained by the test, a constitutive model considering the damage effect, temperature effect, and strain rate effect was established, which was improved by Zhu-Wang-Tang (Z-W-T) constitutive model. It was proved that the fitting curves of constitutive equation were in good agreement with the test curves. The fluctuation amplitude of fitting error was controlled within $\pm 4 \mathrm{MPa}$. The physical meaning of each parameter of the constitutive model is clear, and most of them are fixed values. The selection range of variable parameters and the related change rules are confirmed, which improves the practicability of constitutive model. The constitutive equation can well describe the nonlinear features of this kind of frozen sandstone under impact loading. It was also found that the constitutive equation was applicable to express the dynamic mechanical properties of rock-like materials such as hard rock, soft rock, frozen soil, raw coal, and concrete. It can be referred to the parameter determination method in this paper to study and determine the parameters, reduce the difficulty of parameter selection, and improve the practicability of the constitutive model and parameters, so as to guide the engineering practice better.
\end{abstract}

\section{Introduction}

Most of the mining areas in western China are Jurassic coal seams [1-3], overlying with extremely thick cretaceous water-rich rocks (mainly are fine sandstone, medium sandstone, coarse sandstone, conglomerate, and mudsandstone interbeddings), which has a large porosity, weak cementation, and low strength [4-6]. Freezing sinking technology is often used in shaft construction, but, in the process of blasting excavation, a number of engineering accidents occurred $[7,8]$, such as freezing wall leakage and water gushing, which is due to the cognitive deficiency of Cretaceous red sandstone's mechanical properties under impact load. As the key to represent mechanical properties of rock materials, constitutive relation provides basic parameters for engineering design. Therefore, it is particularly important to study the mechanical properties of such rock under the artificial freezing conditions and impact loads.
At present, many achievements have been made in the study of constitutive models of rock materials under impact load. According to the stress-strain curve's features of soft rock and concrete under dynamic load, Zhao et al. $[9,10]$ improved the existing $\mathrm{Z}-\mathrm{W}-\mathrm{T}$ damage model and established a new dynamic constitutive equation. Xie et al. [11] introduced the theory of continuous damage and statistical strength into the simplified overstress constitutive model and established a simplified damage constitutive equation. Aiming to the dynamic mechanical properties of rock materials, Zhai et al. [12] established a viscoelastic-plastic dynamic constitutive model with considering the damage and derived the differential expression of the constitutive equation, which is based on the damage evolution and element model theory. Based on the continuous factor, strain equivalence principle, and statistical damage theory, Wang et al. [13] defined the damage variables of rock, deduced the damage evolution equation, and established the constitutive 
model of rock using the combination model method. By means of Laplace transform, the damage variables based on pore and fracture deterioration are introduced, and then Cai et al. [14] proposed a new model of the Maxwell body, Bingham body, and damage body in parallel and derived the rock dynamic damage constitutive model relationship at medium and low strain rates. Li et al. [15] developed an excess stress model to analyze the dynamic response of rock joints by using the mechanical conceptual models based on the Hooke, the modified Saint-Venant, and the Newton elements. Wu et al. [16] conducted the sensitivity analysis of the microscopic parameters in the DCA model; meanwhile, he indicated that the model is valid and applicable to describe the dynamic tensile response and can well predict the dynamic tensile strength of rock-like materials. In engineering practice, rocks are in a complex stress state and occurrence environment in most cases. Therefore, it is of great significance to study the constitutive relations of rock materials under the multifactor coupling actions. Therein, on the basis of Z-W-T model, Ma et al. [17, 18] and Zhang et al. [19] introduced the statistical damage theory or used the longitudinal wave velocity to define the damage variable and established the damage dynamic constitutive relation of frozen soil considering the temperature effect. Furthermore, Xie et al. [20] built a micromechanical constitutive model to describe the dynamic compressive deformation of frozen soil and proved the model well reflects the experimental results of frozen soil at different high strain rates and temperatures. Zhang et al. [21] analyzed the dynamic mechanical properties of frozen soil based on HJC constitutive model and used LS-DYNA to simulate the results. According to the dynamic mechanical properties of marble treated at different high temperatures, Wang [22] established a damage evolution equation considering the temperature effect and strain rate effect, which combined the damage theory and strain equivalence principle. It can be seen that the statistical damage theory and strength theory have been widely used in the study of dynamic constitutive relations of rock materials. It lays a foundation and provides the guiding value for the study of mechanical constitutive relation of Cretaceous red sandstone in western China under the freezing temperature field and impact load [23-27]. And the latest research findings in dynamic constitutive model are all about frozen soil. However, few relevant research results have been obtained on the rock's dynamic constitutive relations under the coupling of stress field, temperature field, damage field, and other multiple fields in the freezing sinking of soft rock.

Due to the complexity and indeterminacy of the constitutive parameters, the constitutive model was often difficult to use in engineering practice. In this research, according to the mechanical properties of weakly consolidated soft rock at different freezing temperatures obtained by the SHPB tests, a dynamic constitutive relation improved by the Z-W-T model was established considering the strain rate effect, temperature effect, and damage effect. In addition, the parameters of the model were analyzed and studied, and the parameter values with high practicability were determined. It could provide the reference and design basis on the mineral resources exploitation of artificial freezing project and infrastructure construction in cold regions.

\section{Impact Test of Frozen Red Sandstone}

2.1. SHPB Testing System and Testing Contents. A split Hopkinson pressure bar device was used to complete the dynamic uniaxial compressive tests of frozen red sandstone. The main part of the pressure bar is alloy steel with a diameter of $50 \mathrm{~mm}$, density of $7.8 \mathrm{~g} / \mathrm{cm}^{3}$, elastic modulus of $210 \mathrm{GPa}$, and longitudinal wave velocity of $5172 \mathrm{~m} / \mathrm{s}$. The impact bullet has a length of $300 \mathrm{~mm}$ and a rod diameter of $50 \mathrm{~mm}$. The composition diagram of SHPB test system is shown in Figure 1.

The SHPB impact test is established on the basis of onedimensional stress wave theory and stress uniformity assumption. In order to realize constant strain rate loading and eliminate wave dispersion effect, a pulse shaping technique is used, which is a copper posted on the contact surface of the incident bar and bullet, and Vaseline was applied on both sides of specimen to reduce the friction effect and end effect. The red sandstone specimen is made into a diameter of $50 \mathrm{~mm}$ and a height of $25 \mathrm{~mm}$ following the International Society of Rock Mechanics (ISRM) standards. After saturation, it was put into a low-temperature test chamber for more than $48 \mathrm{~h}$. After the completion of impact pressure and system commissioning, it was rapidly transferred and sandwiched between the incident bar and transmitted bar to complete the impact test. The impact test was controlled within $30 \mathrm{~s}$ to reduce the heat exchange between the specimen and environment.

According to the temperature field distribution of frozen wall, the temperature of the specimens was set as $0^{\circ} \mathrm{C},-10^{\circ} \mathrm{C}$, $-20^{\circ} \mathrm{C}$, and $-30^{\circ} \mathrm{C}$. The impact pressure of SHPB testing system was set as $0.044 \mathrm{MPa}, 0.052 \mathrm{MPa}, 0.06 \mathrm{MPa}$, and $0.075 \mathrm{MPa}$, and the corresponding loading rates were $1800 \mathrm{GPa} \cdot \mathrm{s}^{-1}, 2000 \mathrm{GPa} \cdot \mathrm{s}^{-1}, 2200 \mathrm{GPa} \cdot \mathrm{s}^{-1}$, and $2400 \mathrm{GPa} \cdot \mathrm{s}^{-1}$.

2.2. Stress-Strain Curve Analysis. The stress-strain curves of red sandstone under impact load at different freezing temperatures (i.e., $0^{\circ} \mathrm{C},-10^{\circ} \mathrm{C},-20^{\circ} \mathrm{C}$, and $-30^{\circ} \mathrm{C}$ ) are shown in Figure 2. It shows an obvious segmental character and can be divided into four stages: nonlinear compaction stage, linear elastic stage, plastic development stage, and rapid failure stage. This type of sandstone shows obvious initial nonlinear compaction characteristics in statics [19-21]. However, the proportion of the nonlinear compression segment is very small in the dynamics, which is basically not shown in the stress-strain curves. It is because the microcracks and microholes inside the rock cannot completely close under the high-speed impact, and the dynamic strain increases with the stress faster than in statics, so the form of expression is different. The linear elastic stage accounts for a small proportion of the whole stress-strain curve, and the stress in this stage improves rapidly with the increase of the strain. Its tangential slope is the dynamic elastic modulus of red sandstone, and there is a big difference between the elastic modulus of red sandstone under the impact load and 


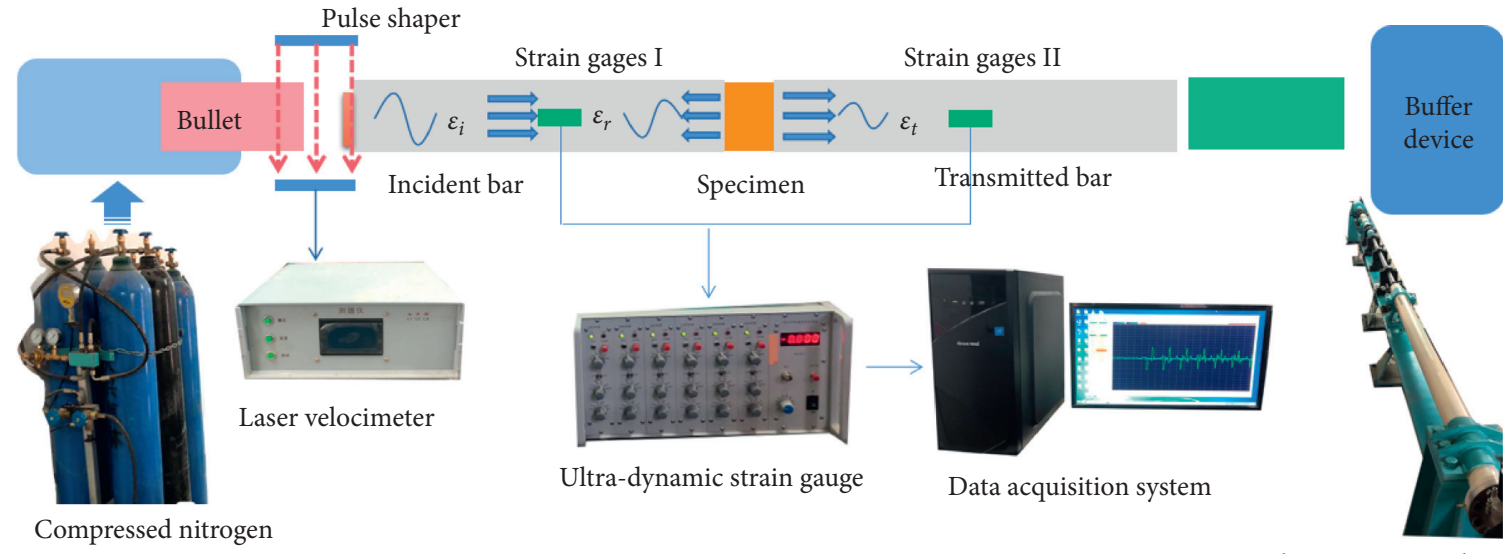

FIGURE 1: SHPB testing system.
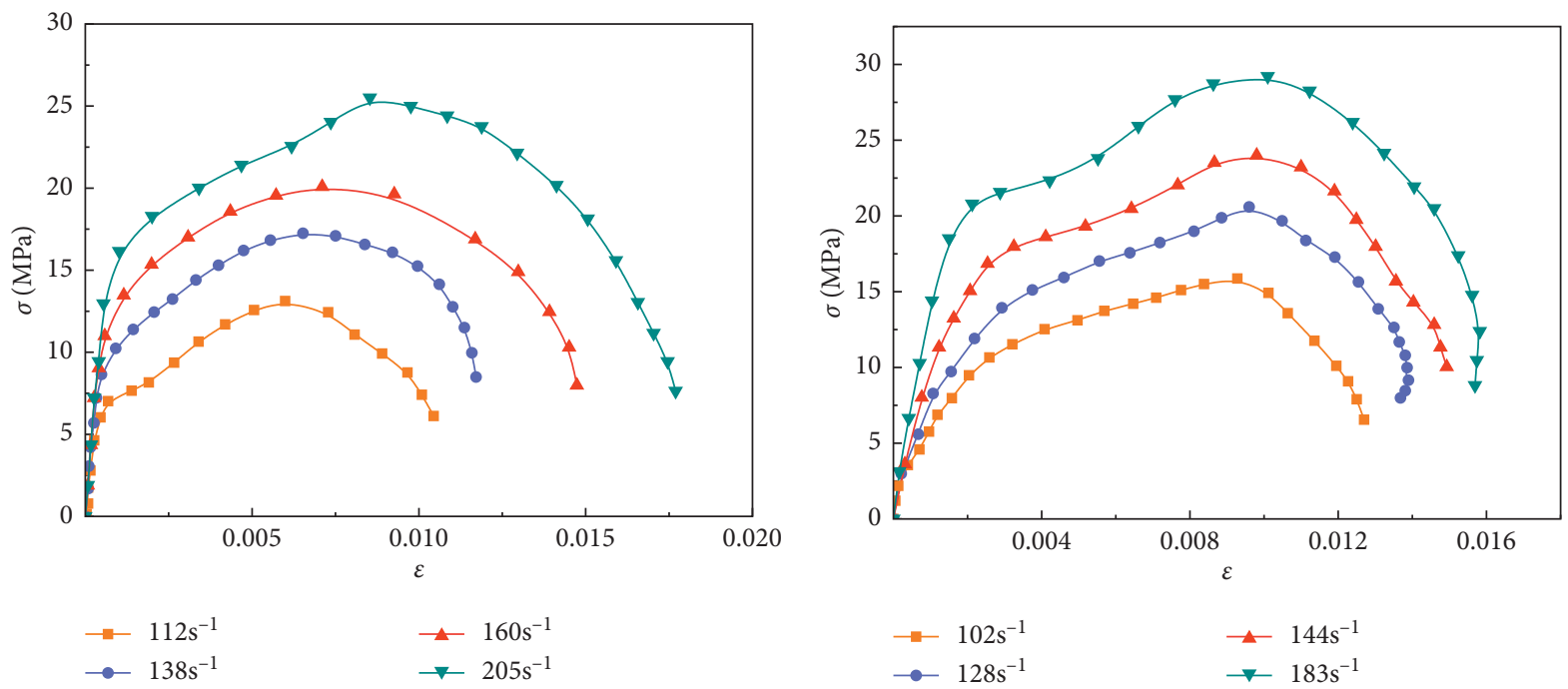

(a)

(b)
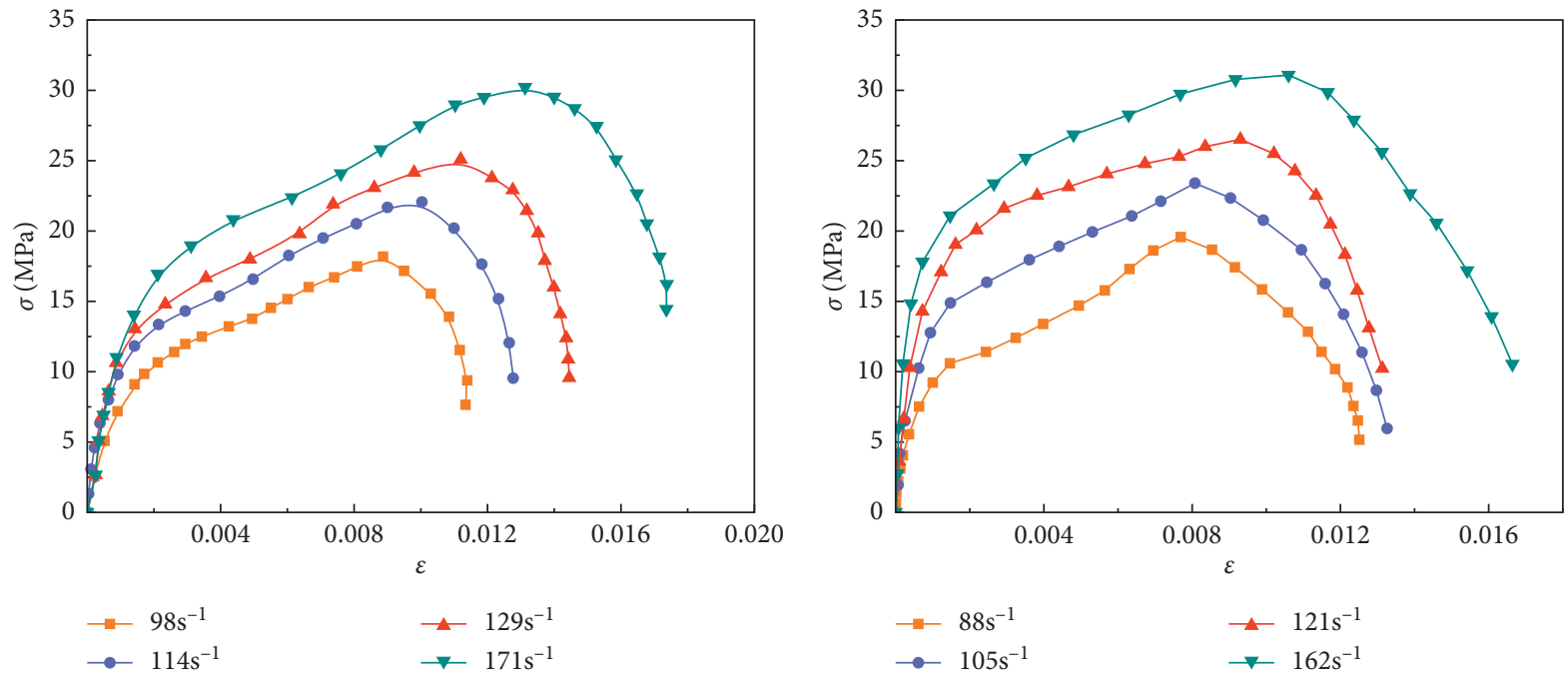

(c)

(d)

Figure 2: Dynamic stress-strain curves of red sandstone. (a) $\mathrm{T}=0^{\circ} \mathrm{C}$. (b) $\mathrm{T}=-10^{\circ} \mathrm{C}$. (c) $\mathrm{T}=-20^{\circ} \mathrm{C}$. (d) $\mathrm{T}=-30^{\circ} \mathrm{C}$. 
static load, which is about 5 to 35 times, showing obvious impact toughness. The plastic development stage accounts for more than $50 \%$ of the total stress curve, and the slope at this stage is small, showing an obvious plastic flow characteristics. Due to the weak cementation among the soft rock particles, it can be interpreted as a comprehensive reflection of strain rate hardening effect, strain rate strengthening effect, and thermal softening effect caused by adiabatic temperature rise. It can be seen from the rapid failure stage of the curve that the ability of red sandstone to resist deformation weakened rapidly after the macroscopic crack is generated; then the macroscopic damage is caused by the crack propagation and penetration, and the specimens lost the load capacity without unloading to 0 . The decline rate of the rock's postpeak curve is accelerated with the decrease of temperature, which shows the enhancement of brittleness.

As shown in Figure 2, the strain rate of red sandstone under the same loading rate decreases but the peak stress increases with the decrease of temperature, and the corresponding peak strain also changes with temperature. It shows that the temperature effect exists in the mechanical characteristics of such rocks under the impact load, which should be considered into the constitutive model.

\section{Constitutive Model of Frozen Red Sandstone}

3.1. Z-W-T Constitutive Model. Z-W-T nonlinear viscoelastic constitutive model can well describe the mechanical properties of solid materials in the range of viscoelastic deformation. Therefore, it has been widely used to study the mechanical properties of concrete, perspex, rock, and other materials in the range of strain rate between $10^{-4} \cdot \mathrm{s}^{-1}$ and $10^{3} \cdot \mathrm{s}^{-1}$. The model consists of one nonlinear spring body and two Maxwell bodies, as shown in Figure 3. Its constitutive equation is as follows:

$$
\begin{aligned}
\sigma= & E_{0} \varepsilon+\alpha \varepsilon^{2}+\beta \varepsilon^{3}+E_{1} \int_{0}^{t} \dot{\varepsilon} \exp \left(-\frac{t-\tau}{\eta_{1}}\right) \mathrm{d} \tau \\
& +E_{2} \int_{0}^{t} \dot{\varepsilon} \exp \left(-\frac{t-\tau}{\eta_{2}}\right) \mathrm{d} \tau .
\end{aligned}
$$

The nonlinear spring in the model is used to describe the equilibrium state of stress. Two different Maxwell bodies, respectively, describe the viscoelastic response under different strain rates and only function in their own "effective responsibility region." Therein, the response time of the lowfrequency part is $10^{1} \mathrm{~s}$ to $10^{2} \mathrm{~s}$, and the high-frequency part is $10^{-4} \mathrm{~s}$ to $10^{-6} \mathrm{~s}$.

3.2. Constitutive Model of Frozen Red Sandstone. When the dynamic constitutive relation of frozen sandstone is expressed by $\mathrm{Z}-\mathrm{W}-\mathrm{T}$ constitutive model, the change of dynamic mechanical relationship under the coupling action of temperature field, damage field, and impact stress field is not considered. And the following improvements are made as follows:

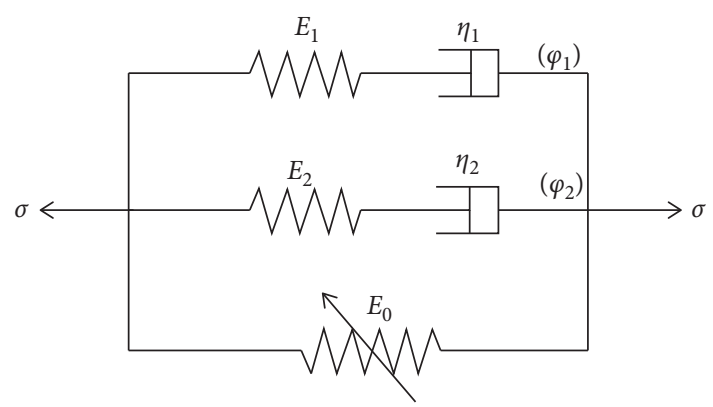

FIgURE 3: Z-W-T constitutive model.

(1) The low-frequency Maxwell body has no time to response in the impact test, so it was simplified to a simple spring with an elastic modulus of $E_{1}$.

(2) The Cretaceous red sandstone contains a large number of defects such as microcracks and micropores. The rock failure process can be regarded as a process of damage development under the impact load. Therefore, the damage body is added in the constitutive model, and the following assumptions are made:

(1) The interior of the rock is continuous and the damage is homogenized.

(2) The impact process is considered to be completed under the constant loading rate.

(3) The microelement strength follows Weibull distribution, and its probability density is

$$
\phi(\varepsilon)=\frac{m}{n} \varepsilon^{m-1} \exp \left(-\frac{\varepsilon^{m}}{n}\right),
$$

where $m$ and $n$ are distribution parameters, which are related to the property and shape of the material.

(3) The interaction between ice crystals and rock particle matrix is enhanced with the decrease of temperature, and the viscosity coefficient is constantly increased. It is the essence of the temperature effect of the mechanical properties of red sandstone under impact load. According to the properties of mechanical elements, the viscous body with viscosity coefficient varying with temperature is added here.

The modified constitutive model is shown in Figure 4. It can be seen that the new model is composed of three parts in parallel, and its stress relation is

$$
\sigma=\sigma_{1}+\sigma_{2}+\sigma_{3}
$$

where the stress of the nonlinear body is

$$
\sigma_{1}=\left(E_{0}+E_{1}\right) \varepsilon+\alpha \varepsilon^{2}+\beta \varepsilon^{3}=E_{\Delta} \varepsilon+\alpha \varepsilon^{2}+\beta \varepsilon^{3} .
$$

The Maxwell body is composed of the elastic element and damping element in series, and its relationship between stress and strain is as follows: 


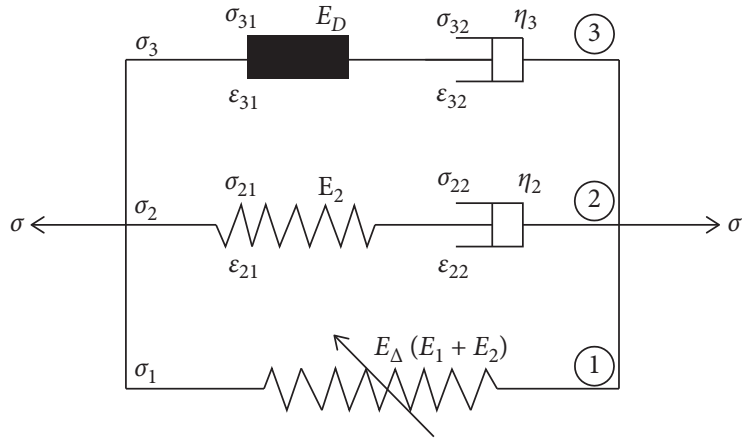

FIGURE 4: The modified model.

$$
\begin{aligned}
\sigma_{2}(t) & =\sigma_{21}(t)=\sigma_{22}(t), \\
\varepsilon_{2}(t) & =\varepsilon_{21}(t)+\varepsilon_{22}(t), \\
\sigma_{21} & =E_{2} \varepsilon_{21}(t), \\
\sigma_{22} & =\eta_{2} \dot{\varepsilon}_{22}(t) .
\end{aligned}
$$

Taking the derivation of (6) and combining (5) and (7) with (8), yield

$$
\dot{\varepsilon}(t)=\frac{\dot{\sigma}(t)}{E_{2}}+\frac{\sigma_{2}(t)}{\eta_{2}} .
$$

After taking the Laplace transform of (9), we get

$$
\begin{aligned}
L(\dot{\varepsilon}(t)) & =L\left(\frac{\dot{\sigma}_{2}(t)}{E_{2}}\right)+L\left(\frac{\sigma_{2}(t)}{\eta_{2}}\right), \\
\dot{\varepsilon} & =\frac{S \varepsilon(S)-\sigma_{2}(0)}{E_{2}}+\frac{\sigma_{2}(S)}{\eta_{2}} .
\end{aligned}
$$

By submitting the boundary condition $\sigma(0)=0$ into (11), we get

$$
\sigma_{2}(S)=\eta_{2} \dot{\varepsilon}\left(\frac{1}{S}-\frac{1}{S+E_{2} / \eta_{2}}\right) .
$$

Taking the inverse Laplace transform of (13) yields

$$
\begin{aligned}
L^{-1}\left(\sigma_{2}(S)\right) & =\eta \dot{\varepsilon} L^{-1}\left(\frac{1}{S}-\frac{1}{S+E_{2} / \eta_{2}}\right), \\
\sigma_{2}(t) & =\eta_{2} \dot{\varepsilon}\left(1-\exp \left(-\frac{E_{2}}{\eta_{2}} t\right)\right) .
\end{aligned}
$$

By substituting $t=\varepsilon / \dot{\varepsilon}$ into (14), the constitutive relation of Maxwell body is

$$
\sigma_{2}(t)=\eta_{2} \dot{\varepsilon}\left[1-\exp \left(-\frac{E_{2} \varepsilon}{\eta_{2} \dot{\varepsilon}}\right)\right] .
$$

The third part of the new model is the damaged body and viscous body in series. According to the statistical damage theory, the damage degree of the specimen is the sum of the defects contained in each microelement, and the probability density relation between the damage variable $D$ and probability density of microelement failure is

$$
\frac{\mathrm{d} D}{\mathrm{~d} \varepsilon}=\phi(\varepsilon) .
$$

After integrating (16) and combining with (3), we get

$$
D=1-\exp \left(-\frac{\varepsilon^{m}}{n}\right) \text {. }
$$

According to (17), the constitutive relation of the damaged body can be written as follows:

$$
\sigma_{31}(t)=(1-D) E_{D} \varepsilon(t)=E_{D} \varepsilon(t) \exp \left(-\frac{\varepsilon^{m}}{n}\right) .
$$

The damaged body is in series with viscous body in new model, according to the derivation of (5) to (15), and replacing $E_{2}$ by $E_{D} \exp \left(-\varepsilon^{m} / n\right)$, the following can be obtained:

$$
\sigma_{3}(t)=\eta_{3} \dot{\varepsilon}\left\{1-\exp \left[-\frac{E_{D^{\varepsilon}}}{\eta_{3} \dot{\varepsilon}} \exp \left(-\frac{\varepsilon^{m}}{n}\right)\right]\right\} .
$$

Therefore, the constitutive equation of the modified model is

$$
\begin{aligned}
\sigma= & E_{\Delta} \varepsilon+\alpha \varepsilon^{2}+\beta \varepsilon^{3}+\eta_{2} \dot{\varepsilon}\left[1-\exp \left(-\frac{E_{2} \varepsilon}{\eta_{2} \dot{\varepsilon}}\right)\right] \\
& +\eta_{3} \dot{\varepsilon}\left\{1-\exp \left[-\frac{E_{D} \varepsilon}{\eta_{3} \dot{\varepsilon}} \exp \left(-\frac{\varepsilon^{m}}{n}\right)\right]\right\} .
\end{aligned}
$$

\section{Experimental Verification of Constitutive Equation}

The constitutive equation and determined parameters are used to fit the test curves of red sandstone at different temperatures under impact load, as shown in Figure 5.

As shown in Figure 5, the test data are well consistent with the fitting curves; the fitting precision is 0.95 to 0.99 . The fitting curves can be divided into three stages, which can well reflect the nonlinear mechanical properties of red sandstone under the action of multiple field coupling. It shows that the constitutive equation can accurately represent the dynamic mechanical properties of red sandstone at different temperatures, and the new model is suitable for the study of dynamic constitutive relations of this type of sandstone.

4.1. Parameter Determination. There are 9 unknown parameters in the constitutive equation. According to the parameter determining method of $\mathrm{Z}-\mathrm{W}-\mathrm{T}$ constitutive model, the quasi-dynamic stress-strain curves of red sandstone at $0^{\circ} \mathrm{C}$ were fitted to determine the parameters $E_{\Delta}$, $\alpha, \beta$, and $E_{2}$, as shown in Table 1 .

According to the creep test of red sandstone at different freezing temperatures, the relation between its viscosity coefficient and temperature is obtained, as shown in 


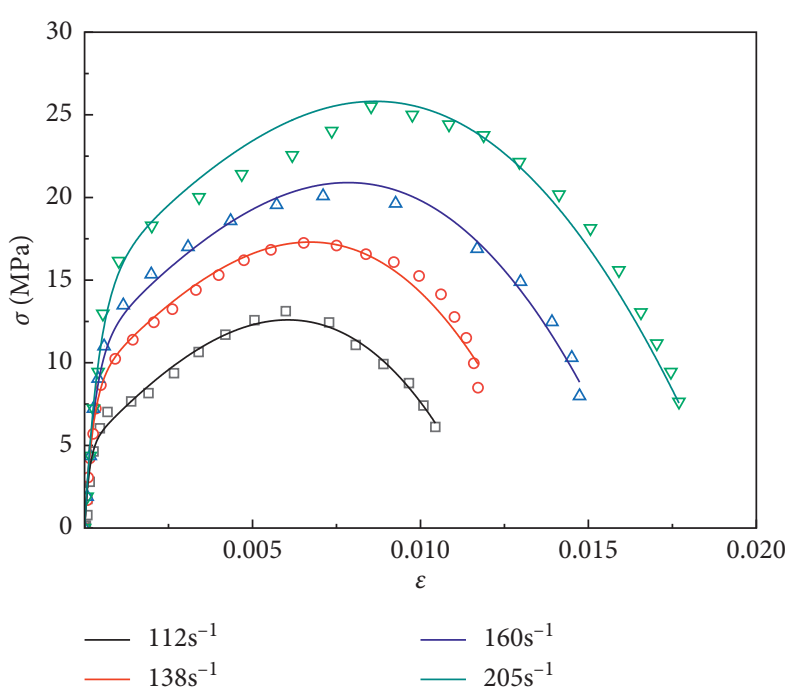

(a)

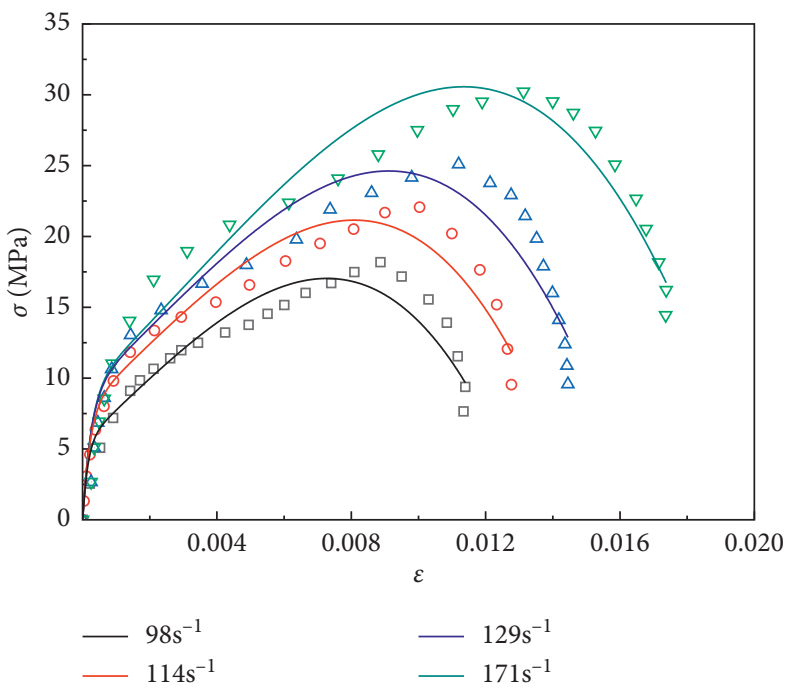

(c)

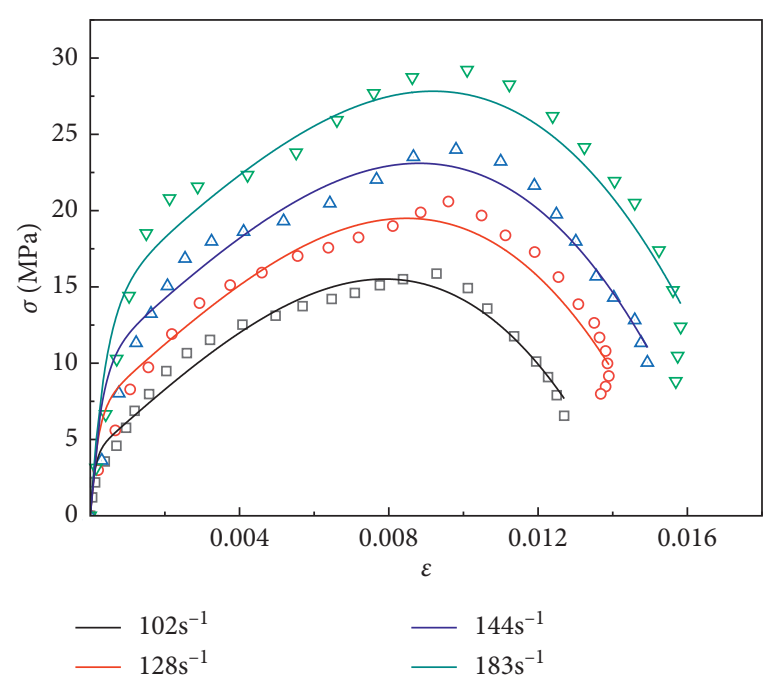

(b)

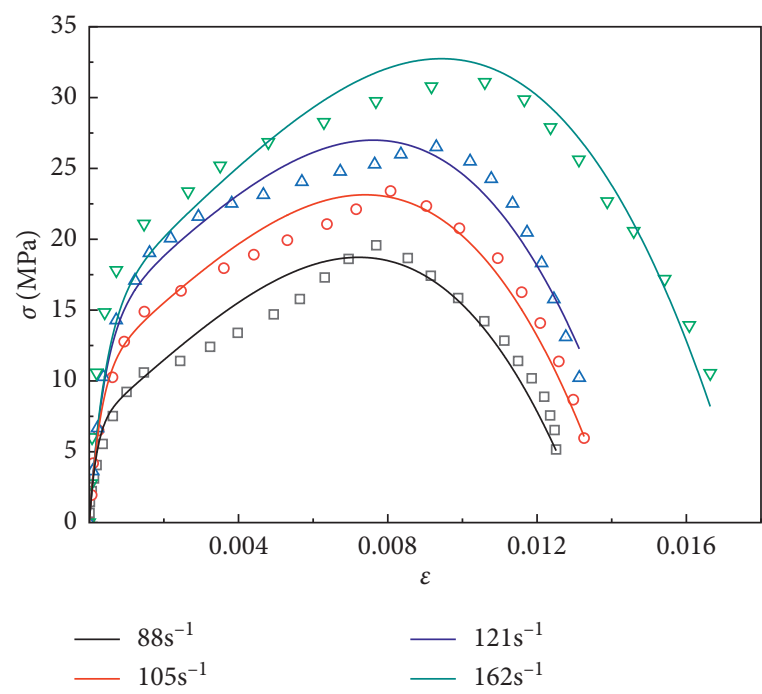

(d)

Figure 5: Experimental curves fitting. (a) $T=0^{\circ} \mathrm{C}$

TABle 1: Constitutive equation parameters.

\begin{tabular}{lccc}
\hline$E_{\Delta}(\mathrm{GPa})$ & $\alpha$ & $\beta$ & $E_{2}(\mathrm{GPa})$ \\
\hline 2 & $-8 E 5$ & $-6.6 E 7$ & 35 \\
\hline
\end{tabular}

Figure 6(a). It can be seen that, with the fall of temperature, the viscosity coefficient of red sandstone increases rapidly, which shows an obvious temperature effect. And its fitting relation is

$$
\eta_{3}=-13 e^{T / 24.36}+16
$$

The remaining 4 parameters in the constitutive equation were obtained by fitting the stress-strain curves obtained by the impact test.

4.2. Parameter Analysis. Table 2 shows the corresponding fitting parameter's value of the constitutive equation. It can be seen that the elastic modulus of the damage body $\left(E_{D}\right)$ is $9 \mathrm{MPa}$, which is a fixed value and does not change with the temperature and strain rate. The parameter $m$ does not change with the strain rate and only relate to the temperature, and its value decreases with the fall of temperature, as shown in Figure 6(b). The relationship is

$$
m=0.02112 e^{T / 25.9}+0.174 \text {. }
$$

The parameter $n$ decreases with the increase of the strain rate and the amplitude of change is small, which is $10^{-3}$. The mean values $(\bar{n})$ of $n$ at each temperature are $0.0558,0.0571$, 0.0585 , and 0.0592 . It can be seen that $\bar{n}$ is increasing with the fall of temperature, as shown in Figure 6(c). The relation between $\bar{n}$ and the freezing temperature is

$$
\bar{n}=-1.16 \times 10^{-4} T+0.05591 .
$$

Figure $6(\mathrm{~d})$ is the data distribution scatter plot of $\eta_{2}$. It can be seen that the value of $\eta_{2}$ increases with the increase of 


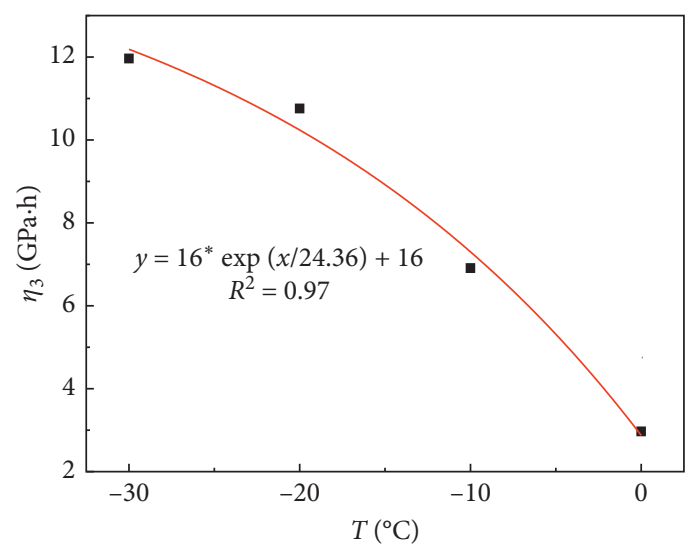

- Experimental data

Fitting curve

(a)

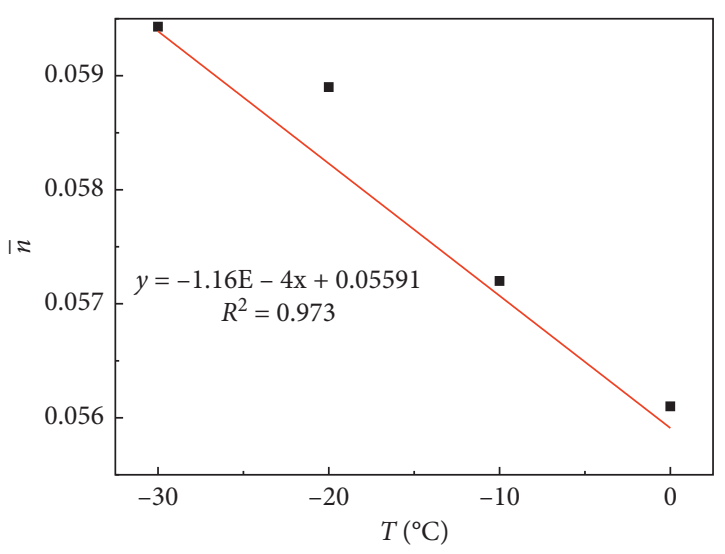

- Experimental data

Fitting curve

(c)

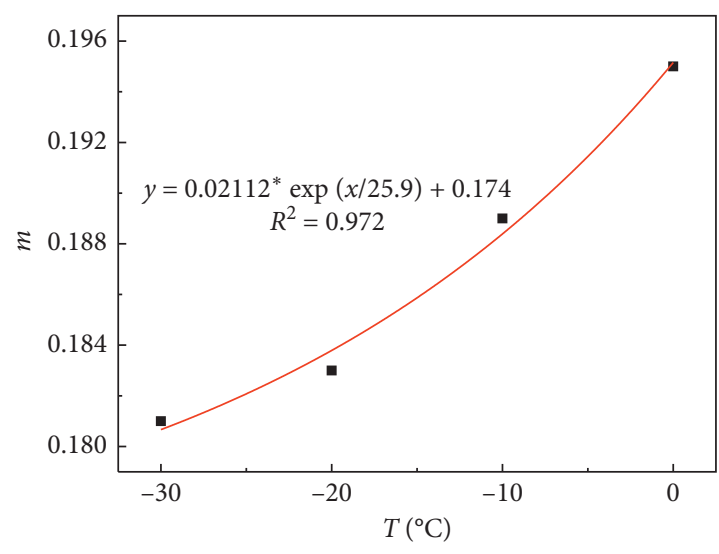

- Experimental data

- Fitting curve

(b)

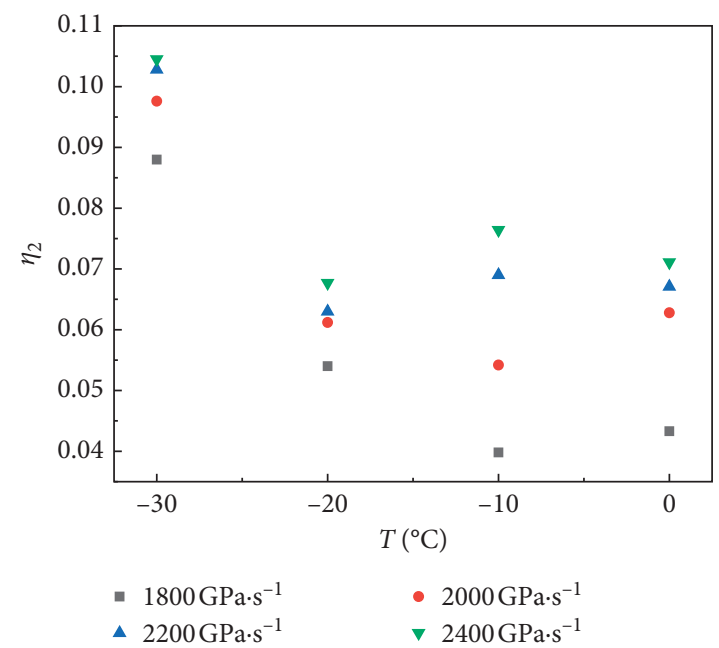

(d)

FIgURE 6: The relation between constitutive parameter and temperature. (a) $\eta_{3}$. (b) $m$. (c) $n$. (d) $\eta_{2}$.

TABLE 2: The fitting parameter values of constitutive model.

\begin{tabular}{lccccccccccc}
\hline$T\left({ }^{\circ} \mathrm{C}\right)$ & Strain rate $\left(\mathrm{s}^{-1}\right)$ & $E_{D}(\mathrm{MPa})$ & $\eta_{2}$ & $m$ & $n$ & Strain rate $\left(\mathrm{s}^{-1}\right)$ & $E_{D}(\mathrm{MPa})$ & $\eta_{2}$ & $m$ & $n$ \\
\hline \multirow{2}{*}{0} & 112 & 9 & 0.0433 & 0.195 & 0.0561 & 160 & 9 & 0.0671 & 0.195 & 0.0557 \\
& 138 & 9 & 0.0628 & 0.195 & 0.0559 & 205 & 9 & 0.0711 & 0.195 & 0.0556 \\
\hline \multirow{2}{*}{-10} & 102 & 9 & 0.0398 & 0.189 & 0.0572 & 144 & 9 & 0.0690 & 0.189 & 0.05705 \\
& 128 & 9 & 0.0542 & 0.189 & 0.0571 & 183 & 9 & 0.0764 & 0.189 & 0.0570 \\
\hline \multirow{2}{*}{-20} & 98 & 9 & 0.0564 & 0.183 & 0.0589 & 129 & 9 & 0.0631 & 0.183 & 0.0584 \\
& 114 & 9 & 0.0612 & 0.183 & 0.0587 & 171 & 9 & 0.0677 & 0.183 & 0.0582 \\
\hline \multirow{2}{*}{-30} & 88 & 9 & 0.0880 & 0.181 & 0.05943 & 121 & 9 & 0.1028 & 0.181 & 0.0592 \\
& 105 & 9 & 0.0976 & 0.181 & 0.05934 & 162 & 9 & 0.1045 & 0.181 & 0.0590 \\
\hline
\end{tabular}

the loading rate at the same temperature, and the magnitude of change is $10^{-2}$. However, $\eta_{2}$ does not show a specific similarity law with the decrease of temperature. Generally speaking, it shows rate dependence, and the values of different temperatures can be selected by interpolation method.

In summary, among the 9 unknown parameters in the constitutive equation, there are 5 fixed values that did not change with the temperature and strain rate, and only 2 parameters change with the temperature. Only the parameter $\eta_{2}$ and $n$ change with temperature and strain rate, and their data range is relatively fixed and the amplitude of change is small. It can be seen that the constitutive equation has few unknown parameters, and its value is relatively fixed. The relevant mechanical parameters can be quantitatively 


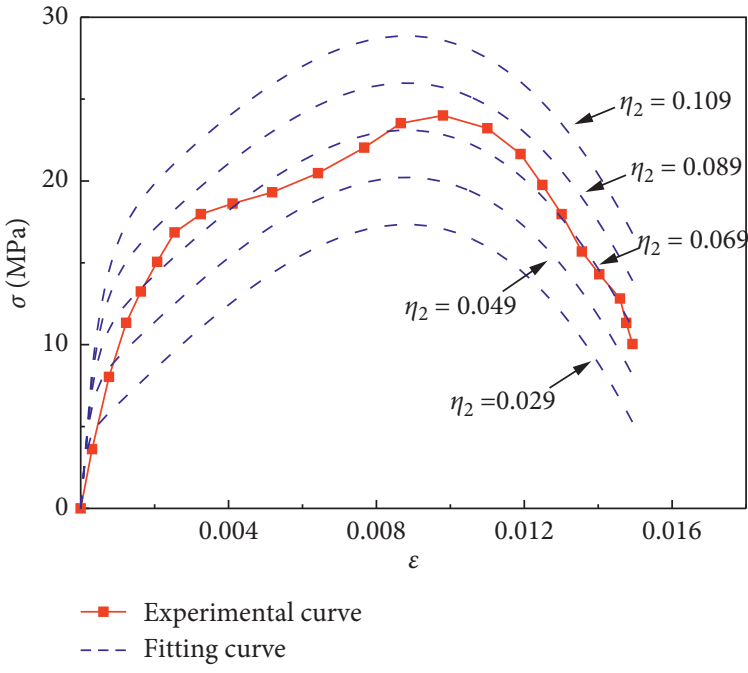

(a)

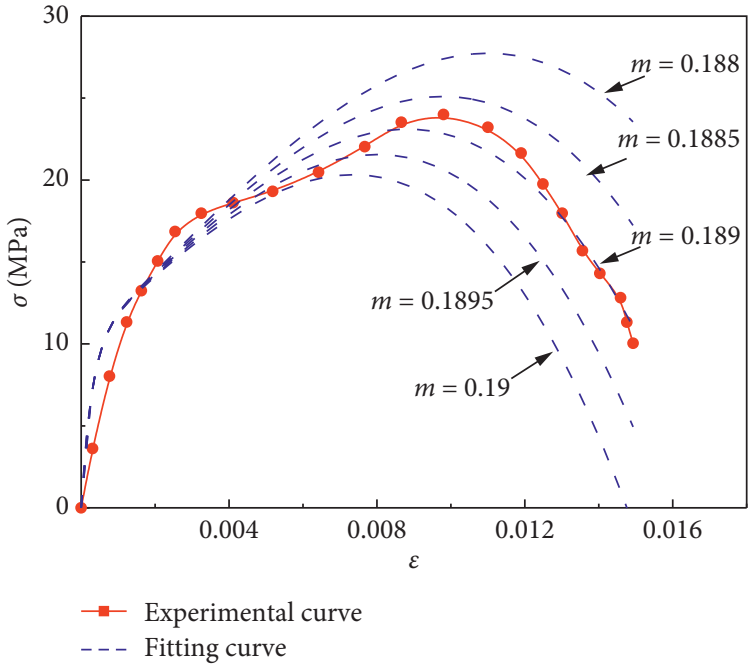

(b)

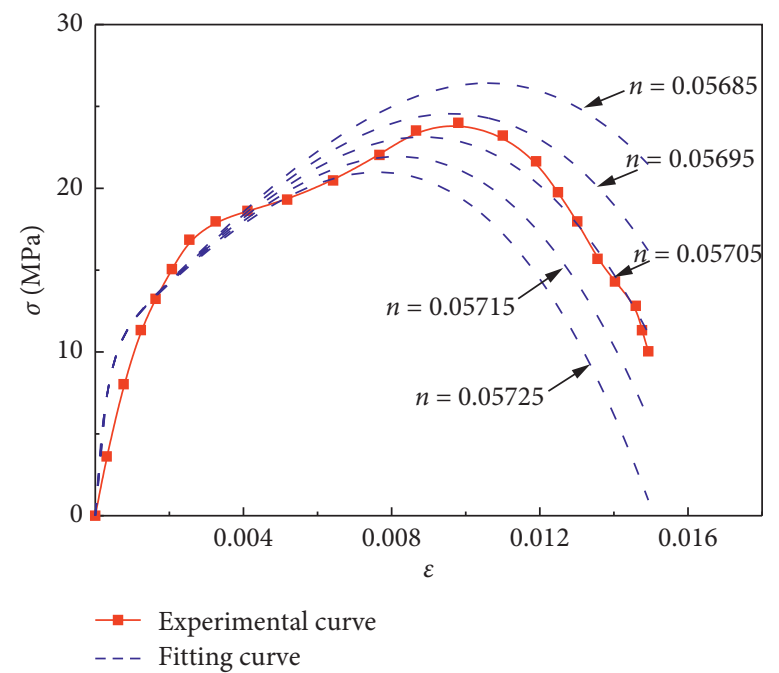

(c)

Figure 7: The influence of parameter values on constitutive curve. (a) $\eta_{2}$. (b) $m$. (c) $n$.

calculated according to (21) to (23) in practical engineering applications. Therefore, it has certain practical value.

4.3. Parameter Sensitivity Analysis. A group of experimental data and the corresponding fitting parameter values are randomly selected to analyze the influence of the changing parameters $\left(\eta_{2}, m\right.$, and $\left.n\right)$ on constitutive equation. Firstly, $\eta_{2}$ of high-frequency Maxwell body is analyzed, and the influence of its value change to the constitutive curve is observed after fixing the values of other parameter. As shown in Figure $7(\mathrm{a})$, with the increase of $\eta_{2}$, the fitting curve-up translation as a whole, and the linear elastic stage becomes longer but the slope remains unchanged. And the shape of the fitting curve does not change. It can be seen that the change of $\eta_{2}$ only affects the magnitude of the peak strength. Therefore, it is the intensity control parameter.

Figures 7(b) and 7(c) show the influence of Weibull distribution parameters $m$ and $n$ to the curve, respectively. It can be seen that, with the increase of $m$ and $n$, the end of the fitting curve changes from divergence to convergence and the peak stress and corresponding peak strain decrease continuously. Meanwhile, the slope of plastic stage also decreases gradually, and the unloading strength of postpeak curve decreases continuously, which shows an enhancement of the rock's brittleness. The parameters $m$ and $n$ have the same effect on the curve and jointly control the curve's plasticity and the failure stage of the development trend. However, from the view of the influence of parameter values on the curve, when the stress curve has the same change, the change of $m$ is 0.0005 , but $n$ is 0.0001 , so $n$ has a higher sensitivity to the curve.

4.4. Error Analysis. Figure 8 shows the relationship between the difference of red sandstone's test curve to the constitutive fitting curve and strain at different temperatures. It can be seen that the fitting error $(\Delta \sigma)$ fluctuates with the increase of 


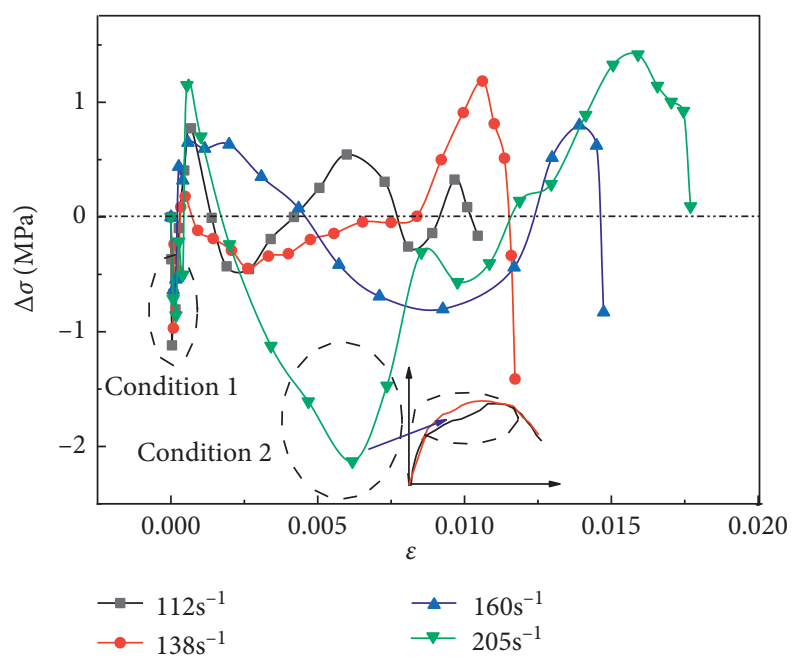

(a)

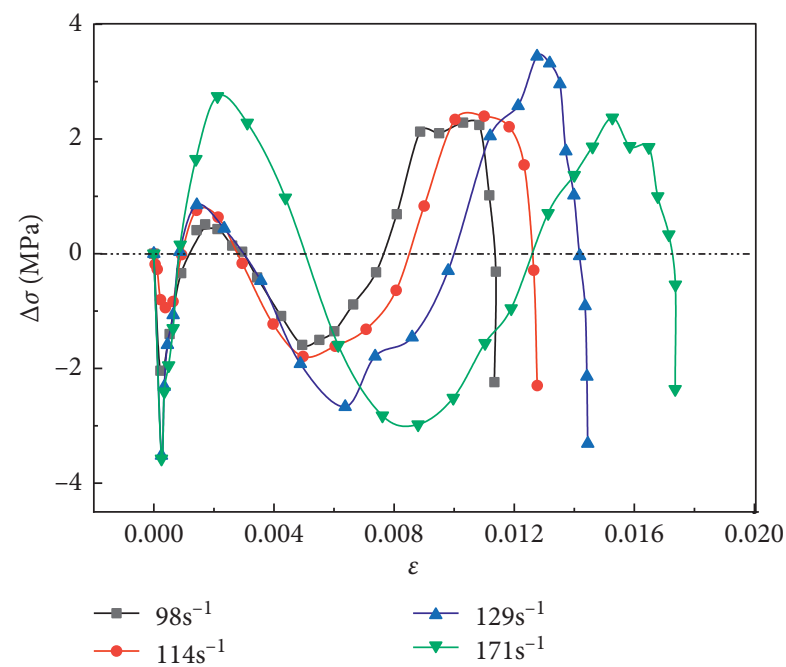

(c)

FIgURE 8: Error analysis of fitting curve. (a) $T=0^{\circ} \mathrm{C}$

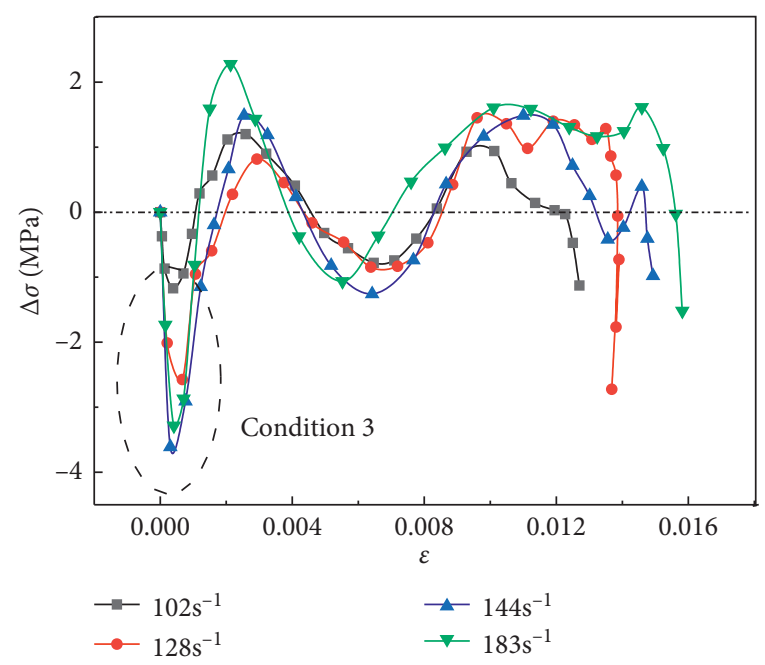

(b)

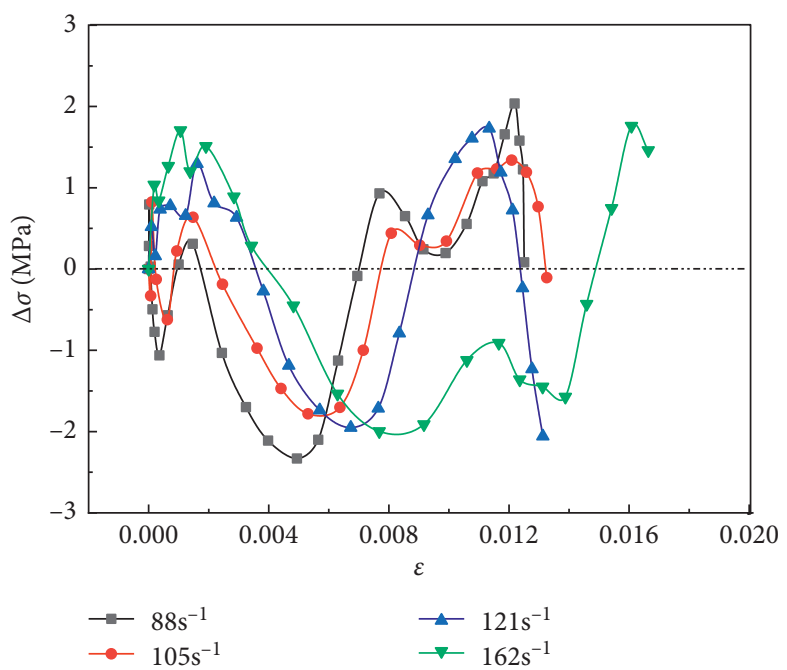

(d)

C. (b) $\mathrm{T}=-10^{\circ} \mathrm{C}$. (c) $\mathrm{T}=-20^{\circ} \mathrm{C}$. (d) $\mathrm{T}=-30^{\circ} \mathrm{C}$.

strain, but the fluctuation is small, which is controlled among $-4 \mathrm{Mpa}$ to $4 \mathrm{Mpa}$. Therefore, the new constitutive model can well reflect the mechanical properties of sandstone under impact load.

In combination with the sensitivity analysis of parameters, several conditions of fitting curve error are explained here. (1) In condition 1, it can be seen that the absolute value of $\Delta \sigma$ is large in the initial stage of strain, which is caused by the fact that the small part of nonlinear compression segment appearing in the test curve is not expressed in the fitting curve. (2) In condition 2, the slope of the fitting curve in the plastic development stage is decreasing all the time, while the red sandstone shows the strain hardening stage before reaching the peak strength under the action of the high strain rate, which makes the fitting accuracy declined and $\Delta \sigma$ is relatively large. (3) In condition 3, since the variation of elastic modulus with temperature is not considered in the determination of constitutive parameters, there will be fluctuation in the initial section of the error curve. When the value of $\Delta \sigma$ is positive, it means that the elastic modulus of the fitting curve is smaller than the actual value, and when $\Delta \sigma$ is negative, it means that the elastic modulus of the fitting curve is bigger than the actual value. Therefore, the selection of parameters can be further improved according to the error curves.

\section{Applicability Analysis of Constitutive Equation}

The constitutive model established in this research has good applicability to describe the dynamic mechanical properties of Cretaceous red sandstone under artificial freezing conditions, and it can be conveniently applied to engineering practice. And the applicability of the constitutive model on other rock materials is further discussed. Since the viscous body in the constitutive equation is considered as the influence of temperature effect on the constitutive relation of red sandstone, it can be treated as an unknown parameter 


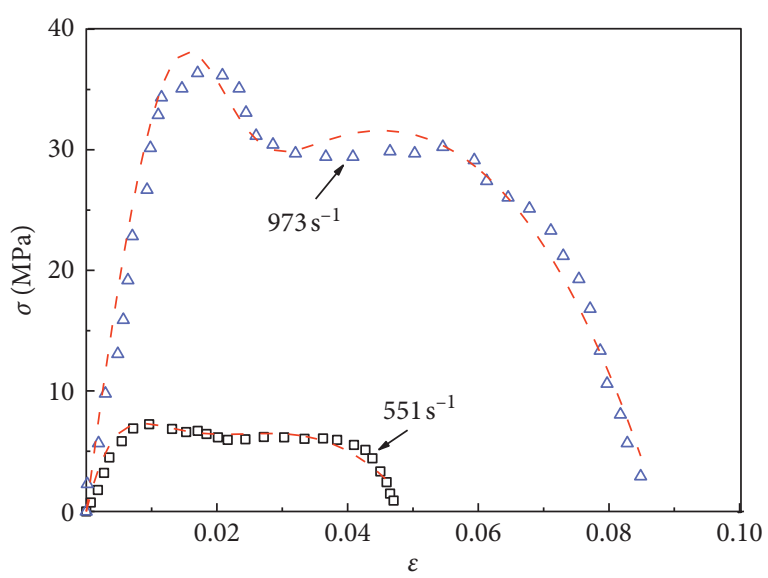

- - Fitting curve

(a)

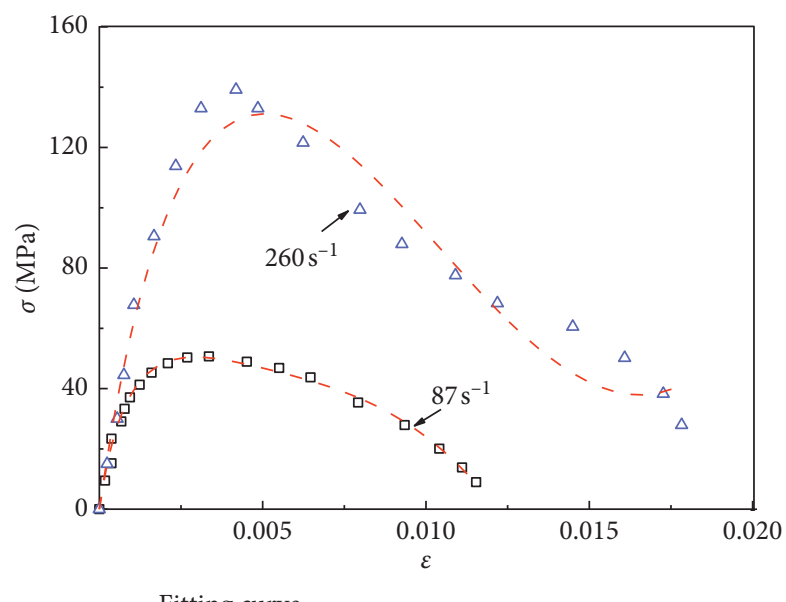

- - Fitting curve

(c)

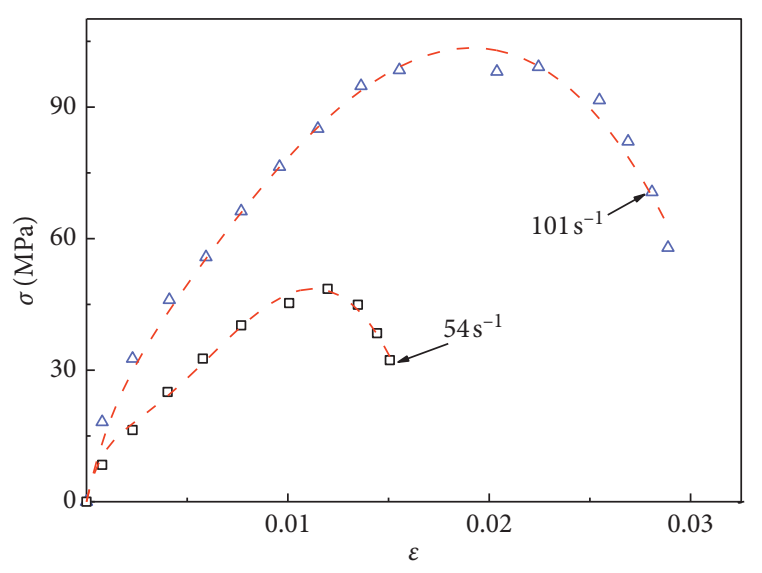

- - Fitting curve

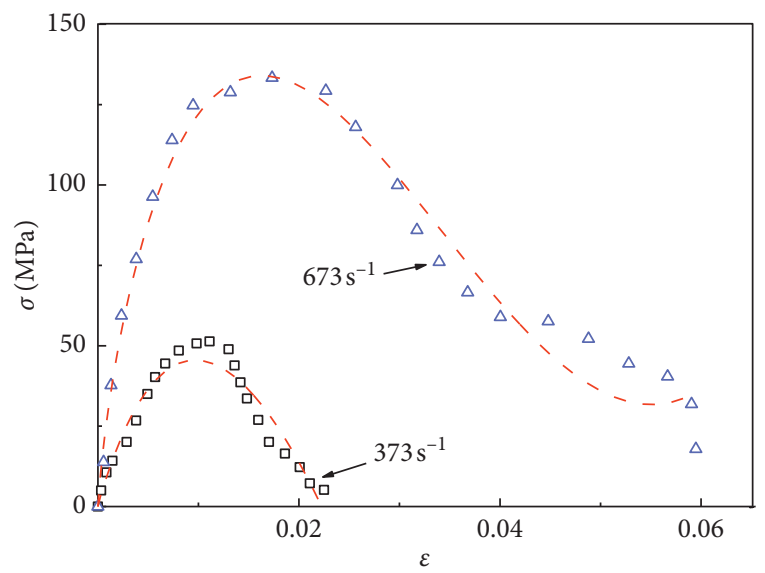

- - - Fitting curve

(b)

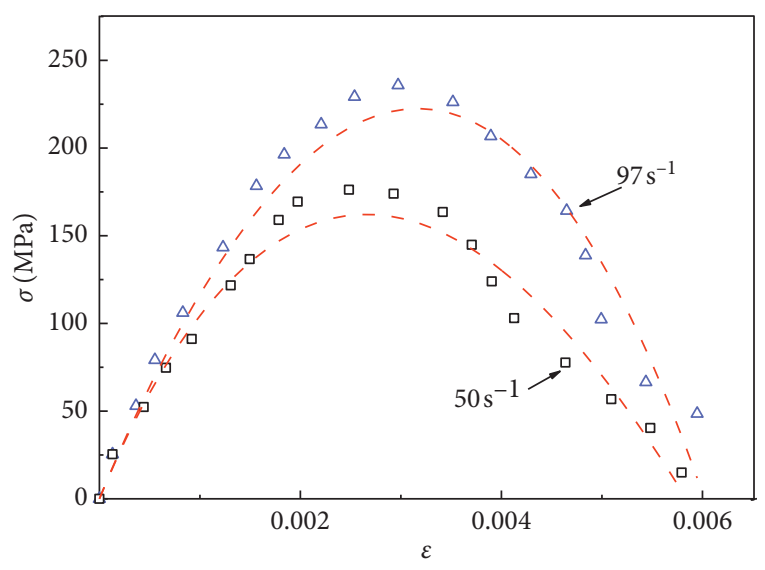

- - Fitting curve

(d)

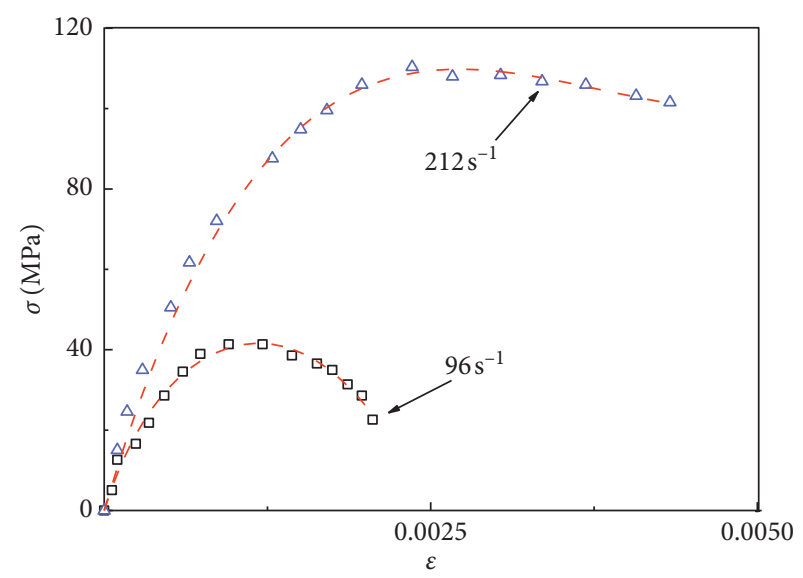

- - - Fitting curve

(e)

(f)

FIgURE 9: Continued. 


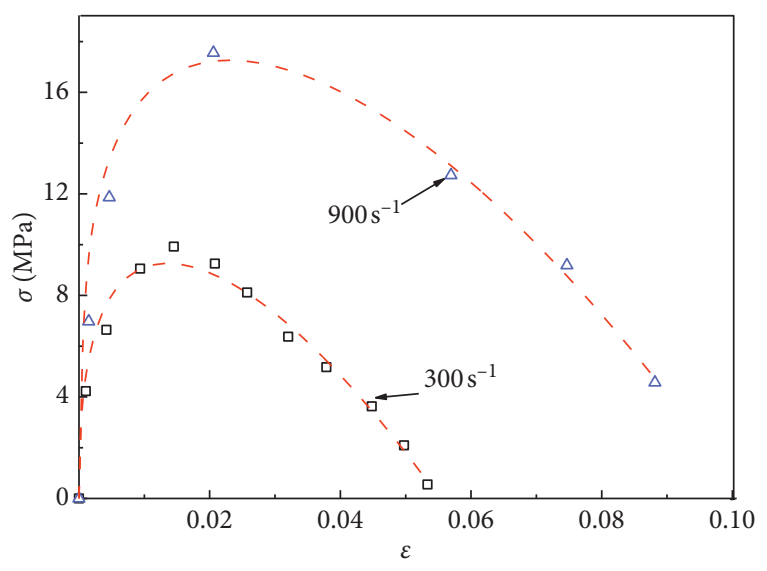

- - Fitting curve

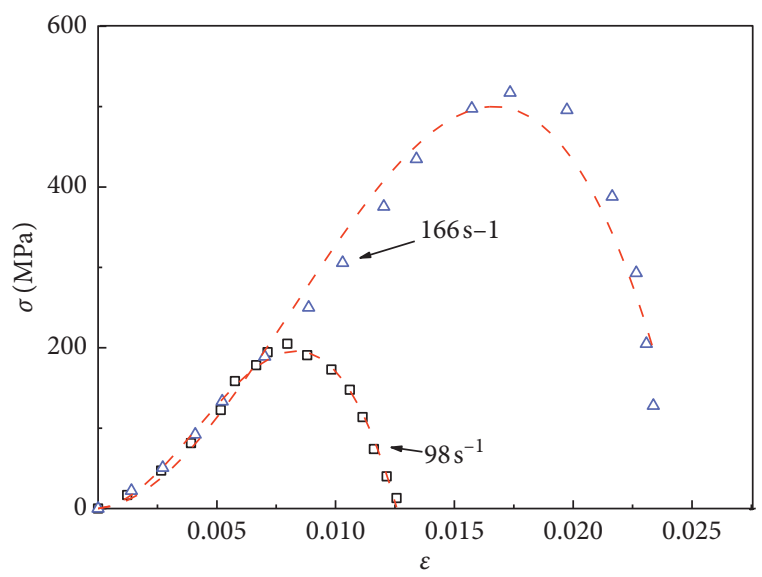

- - Fitting curve

(g)

(h)

FIGURE 9: Universal verification of constitutive equation. (a) Mudstone-experimental data cited from literature [9]. (b) Sandy mud-experimental data cited from literature [10]. (c) Concrete-experimental data cited from [12]. (d) Granite-experimental data cited from [12]. (e) Red sandstone-experimental data cited from [28]. (f) Raw coal-experimental data cited from [29]. (g) Frozen soil-experimental data cited from [19]. (h) Limestone-experimental data cited from [30].

TABLE 3: The fitting parameter values of each material.

\begin{tabular}{lcccccccccccc}
\hline Materials & Strain rate $\left(\mathrm{s}^{-1}\right)$ & $E_{\Delta}(\mathrm{GPa})$ & $\alpha$ & $\beta$ & $\eta_{2}$ & $E_{2}(\mathrm{GPa})$ & $\eta_{3}$ & $E_{D}(\mathrm{GPa})$ & $m$ & $n$ \\
\multirow{2}{*}{ Mudstone } & 551 & 0.2 & 6326 & -205497 & $2 E-6$ & 2 & 1 & 2 & 3 & 0.0028 \\
& 973 & 0.2 & 6087 & -128610 & 0.06 & 2 & 1 & 2 & 3 & $6.6 E-6$ \\
\hline \multirow{2}{*}{ Sandy mudstone } & 373 & 1 & -202700 & 667140 & 0.2 & 10 & 1 & 60 & 0.3 & 0.00242 \\
& 637 & 1 & -207160 & 2397860 & 0.2 & 10 & 1 & 60 & 0.3 & 0.07 \\
\hline \multirow{2}{*}{ Concrete } & 87 & 0.1 & -1954000 & $8.14 E 7$ & 0.5 & 10 & 1 & 65 & 1 & 0.00814 \\
& 260 & 0.1 & 325760 & $-5 E 7$ & 0.5 & 10 & 1 & 65 & 1 & 0.00167 \\
\hline \multirow{2}{*}{ Granite } & 50 & 10 & $-2.29 E 7$ & $7.59 E 8$ & 100 & 100 & 1 & 30 & 1 & 0.003 \\
& 97 & 10 & $-1.09 E 7$ & $-1.23 E 9$ & 100 & 100 & 1 & 30 & 1 & 0.003 \\
\hline \multirow{2}{*}{ Red sandstone } & 54 & 1 & 822890 & 20940 & 0.1 & 10 & 1 & 10 & 1 & 0.00192 \\
& 101 & 1 & $-5.1 E 7$ & $-8.95 E 6$ & 0.759 & 10 & 1 & 10 & 1 & 0.00192 \\
\hline \multirow{2}{*}{ Raw coal } & 96 & 0.1 & 8216000 & $-5.52 E 9$ & 1 & 1 & 1 & 100 & 1 & 0.00132 \\
& 212 & 0.1 & $-1.15 E 7$ & $1.31 E 9$ & 1 & 1 & 1 & 100 & 1 & 0.02 \\
\multirow{2}{*}{ Frozen soil } & 300 & 0.1 & -5207 & 17900 & 0.006 & 10 & 1 & 12 & 0.3 & 0.1 \\
& 900 & 0.1 & -2622 & 3571 & 0.006 & 10 & 1 & 12 & 0.3 & 0.088 \\
\hline \multirow{2}{*}{ Limestone } & 98 & 1 & 7967000 & $-6.45 E 8$ & 0.002 & 10 & 1 & 1 & 1 & 0.1 \\
& 166 & 1 & 5178590 & $-2.09 E 8$ & 0.002 & 10 & 1 & 1 & 1 & 0.1 \\
\hline
\end{tabular}

when characterizing the dynamic properties of other materials. On this basis, the dynamic stress curves of mudstone and sandy mudstone obtained by Zhao et al. [9, 10], the dynamic stress curves of concrete and granite obtained by Zhai et al. [12], the dynamic stress curves of red sandstone obtained by Yang et al. [28], the dynamic stress curves of raw coal obtained by Zhang et al. [29], the dynamic stress curves of frozen soil obtained by Zhang et al. [19], and the dynamic stress curves of limestone obtained by Zou et al. [30] are quoted in this research. The applicability of the constitutive equation is verified, and the fitting results of all materials are shown in Figure 9. It can be seen that the stress curves of each material under impact load are different in shape and have their own features. The strain rate of test data is distributed between $50 \mathrm{~s}^{-1}$ and $1000 \mathrm{~s}^{-1}$, and the peak strength of the material is distributed between $5 \mathrm{MPa}$ and $500 \mathrm{MPa}$, with a wide distribution range. From the fitting results of the constitutive equation, the fitting curves and experimental data have good consistency in soft rock, hard rock, frozen soil, concrete, and raw coal, which indicates that the constitutive equation established in this research has good universality in representing the constitutive relations of rock materials.

Table 3 shows the fitting parameters of the constitutive equation for each material. The following was observed. (1) Although there are 9 unknown parameters in the constitutive equation, the values of 5 to 7 constitutive parameters of the same material under different strain rates are the same and do not change with the strain rates. In addition, the fitting parameter values of $\eta_{3}$ in different materials are the 
same, all of which are 1 . Therefore, it can be set as a fixed value in practical application. (2) The physical meaning of each parameter value is correct. Among them, the elasticity coefficient in the high-frequency Maxwell body $\left(E_{2}\right)$ is always an order of magnitude larger than the nonlinear body $\left(E_{\Delta}\right)$, which conforms to the rock's mechanical response mechanism under impact load. (3) Although the nonlinear coefficient $(\alpha$ and $\beta)$ are relatively complex in numerical value, they provide the possibility for the constitutive equation to be applied to the universality of rock-like materials.

In conclusion, the applicability of the constitutive equation in the expression of other material's dynamic properties was further discussed in this paper, but the possible regularity in the fitting parameters of each material was not further studied. In practical engineering applications, the parameters should be studied and determined according to each material's dynamic properties and the parameter determination method in this research. We cut down the variables as much as possible, so as to reduce the difficulty of parameter selection and improve the practicality of constitutive model and parameters.

\section{Conclusions}

In this research, a new constitutive model considering the temperature effect, strain rate effect, and damage effect was established based on Z-W-T model. The parameter sensitivity and fitting error were analyzed. And the applicability of constitutive model is further discussed. The conclusions are as follows:

(1) According to the stress-strain curve features of red sandstone under impact load, taking the change of rock's viscosity coefficient with temperature into consideration, a nonlinear viscoelastic damage constitutive model considering the temperature effect, strain rate effect, and damage effect was established by improving the $\mathrm{Z}-\mathrm{W}-\mathrm{T}$ model. Therein, the strength of damage microelement was assumed to follow the Weibull distribution, and its constitutive equation is deduced.

(2) The test data are in good agreement with the fitting curves of constitutive equation. The fitting error fluctuates between $-4 \mathrm{MPa}$ and $4 \mathrm{MPa}$, the fitting accuracy is 0.95 to 0.99 , which shows that the constitutive equation can well represent the dynamic properties of frozen red sandstone, and the model is suitable for studying the dynamic constitutive relation of Cretaceous red sandstone.

(3) The fitting parameters of constitutive equation are simple. Sensitivity analysis was carried out for the variable parameters, and $\eta_{2}$ only affects the peak strength, which is the strength control parameter. $m$ and $n$ affect the development trend of the plastic stage and failure stage of the curve, but $n$ has a higher sensitivity to the curve. The physical meaning of each parameter is clear. Meanwhile, the parameter range and the related change rule are determined, which improves the practicability of constitutive model and provides reference and basis for engineering practice.

(4) The constitutive model can well reflect the nonlinear characteristics of red sandstone under impact load. It is proved that the constitutive equation is applicable to the dynamic performance characterization of rock materials such as hard rock, soft rock, frozen soil, raw coal, and concrete. In engineering practice, the parameter values can be studied and determined by referring to the parameter determination method in this research, which can reduce the difficulty of parameter selection and improve the practicability of constitutive model.

\section{Data Availability}

The data used to support the findings of this study are included within the article.

\section{Conflicts of Interest}

The authors declare that there are no conflicts of interest regarding the publication of this paper.

\section{Acknowledgments}

The work was supported by the National Natural Science Foundation of China (nos. 51404193 and 41702339), the Shaanxi Provincial Natural Science Foundation (nos. 2018JQ4026 and S2015YFJQ1194), and the China Postdoctoral Fund (no. 2015M572581). The authors thank the Xi'an University of Science and Technology for providing the experiment conditions.

\section{References}

[1] W. M. Wang, L. Wang, and C. Q. Dai, "Frozen wall deformation analysis in weakly cemented soft rock based on layered calculation of strength," Chinese Journal of Rock Mechanics and Engineering, vol. 30, no. S2, pp. 4110-4115, 2011.

[2] Z. Zhao, W. Sun, M. Zhang, X. Gao, and S. Chen, "Fracture mechanical behavior of cracked cantilever roof with large cutting height mining," Shock and Vibration, vol. 2020, Article ID 1641382, 10 pages, 2020.

[3] M. Q. Meng, Z. Sun, C. Wang, X. He, and Y. Xiao, "Size effect on mudstone strength during freezing-thawing cycle," Environmental Geotechnics, vol. 78, no. 15, pp. 435.1-435.14, 2018.

[4] Z. Zhao, W. Sun, S. Chen, W. Wang, and Q. Wang, "Coupling model of jointed rock mass and rock bolt in offshore LPG underground storage," Energy Science \& Engineering, vol. 8, no. 5, pp. 1468-1483, 2020.

[5] L. Wang, H. M. Su, S. G. Chen, and Y. Qin, "Nonlinear dynamic constitutive model of frozen sandstone based on Weibull distribution," Advances in Civil Engineering, vol. 2020, Article ID 6439207, 10 pages, 2020.

[6] L. H. Song, H. G. Ji, and B. S. Yang, "Physical and mechanical characteristic of rocks with weakly cemented strata in western 
representative mining area," Journal of China Coal Society, vol. 43, no. 3, pp. 866-874, 2019.

[7] Z. H. Zhao, M. Z. Zhang, Q. Ma, and B. S. Chen, "Deviation effect of coaxiality on the rock brazilian split," Advances in Mathematical Physics, vol. 2020, Article ID 5782457, 8 pages, 2020.

[8] L. Y. Tang, Y. Du, L. Liu, L. Jin, G. Y. Li, and L. J. Yang, "Effect mechanism of unfrozen water on the frozen soil-structure interface during the freezing-thawing process," Geomechanics and Engineering, vol. 22, no. 3, pp. 245-254, 2020.

[9] G. M. Zhao, L. X. Xie, and X. R. Meng, "A constitutive model for soft rock under impact load," Explosion and Shock Waves, vol. 2, pp. 126-132, 2013.

[10] L. X. Xie, G. M. Zhao, and X. R. Meng, "Research on damage viscoelastic dynamic constitutive model of soft rock and concrete materials," Chinese Journal of Rock Mechanics and Engineering, vol. 32, no. 4, pp. 857-864, 2013.

[11] L. X. Xie, G. M. Zhao, and X. R. Meng, "Research on excess stress constitutive model of rock under impact load," Chinese Journal of Rock Mechanics and Engineering, vol. 32, no. S1, pp. 2772-2781, 2013.

[12] Y. Zhai, J. H. Zhao, X. C. Li, and J. C. Ren, "Study of damage viscoelastic-plastic dynamic constitutive model of rock materials," Chinese Journal of Rock Mechanics and Engineering, vol. 30, no. S2, pp. 3820-3824, 2011.

[13] C. Wang, L. Z. Tang, L. P. Chen, Y. Chen, T. Liu, and Y. H. Wei, "Damage characteristics and constitutive model of rock under three-dimensional high static load and frequent dynamic disturbance," Rock and Soil Mechanics, vol. 38, no. 8, pp. 2286-2296, 2017.

[14] C. Cai, K. S. Wu, X. H. Yuan, and S. J. Chen, "Damage constitutive model of rock under medium and low strain rates," Rock and Soil Mechanics, vol. 36, no. 3, pp. 795-802, 2015.

[15] H. Li, T. Zhou, J. H. Deng, J. H. Yin, and J. B. Zhu, “An excess stress model for capturing rate-dependent compressive behavior of rock joint and its validation and applications," International Journal of Rock Mechanics and Mining Sciences, vol. 128, Article ID 104267, 2020.

[16] B. B. Wu, W. Yao, and K. W. Xia, "Theoretical modeling of dynamic tensile response of Laurentian granite using the dominant crack algorithm," International Journal of Rock Mechanics and Mining Sciences, vol. 123, Article ID 104077, 2019.

[17] D. D. Ma, Q. Y. Ma, and P. Yuan, "SHPB tests and dynamic constitutive model of artificial frozen sandy clay under confining pressure and temperature state," Cold Regions Science and Technology, vol. 167, Article ID 102858, 2019.

[18] D. Ma, Q. Ma, P. Yuan, and K. Huang, "SHPB tests and dynamic constitutive model of artificial frozen sandy clay under confining pressure and temperature state," Cold Regions Science and Technology, vol. 136, pp. 37-43, 2017.

[19] H. D. Zhang, Z. W. Zhu, S. C. Song, G. Z. Kang, and J. G. Ning, "Dynamic behavior of frozen soil under uniaxial strain and stress conditions," Applied Mathematics and Mechanics (English Edition), vol. 34, no. 2, pp. 229-238, 2013.

[20] Q. Xie, Z. Zhu, and G. Kang, "A dynamic micromechanical constitutive model for frozen soil under impact loading," ACTA Mechanica Solida Sinica, vol. 29, no. 1, pp. 13-21, 2016.

[21] D. Zhang, Z. W. Zhu, and Z. J. Liu, "Dynamic mechanical behavior and numerical simulation of frozen soil under impact loading," Shock and Vibration, vol. 2016, Article ID 3049097, 16 pages, 2016.
[22] Z. L. Wang, H. Shi, and J. G. Wang, "Mechanical behavior and damage constitutive model of granite under coupling of temperature and dynamic loading," Rock Mechanics and Rock Engineering, vol. 51, no. 10, pp. 3045-3059, 2018.

[23] H. M. Zhang, X. Z. Meng, and G. S. Yang, "A study on mechanical properties and damage model of rock subjected to freeze-thaw cycles and confining pressure," Cold Regions Science and Technology, vol. 174, Article ID 103056, 2020.

[24] Y. J. Shen, H. W. Yang, J. M. Xi, Y. Yang, Y. Z. Wang, and $X$. Wei, "A novel shearing fracture morphology method to assess the influence of freeze-thaw actions on concrete-granite interface," Cold Regions Science and Technology, vol. 169, Article ID 102900, 2019.

[25] H. L. Jia, S. Ding, Y. Wang, F. Zi, Q. Sun, and G. S. Yang, “An NMR-based investigation of pore water freezing process in sandstone," Cold Regions Science and Technology, vol. 168, Article ID 102893, 2019.

[26] M. Q. Meng, L. Wang, X. Jiang, C. G. Wang, H. L. Liu, and Y. Xiao, "Single-particle crushing test and numerical simulation of coarse grains based on size effect," Roil and Soil Mechanics, vol. 41, no. 9, pp. 1-11, 2020.

[27] G. S. Yang, Y. Wei, Y. J. Shen et al., "Mechanical behavior of frozen saturated sandstone under triaxial compression and strength forecast models," Chinese Journal of Rock Mechanics and Engineering, vol. 38, no. 4, pp. 683-694, 2019.

[28] Y. Yang, R. S. Yang, J. G. Wang, S. Z. Fang, and N. N. Zhang, "Experimental study on dynamic mechanical properties of red sandstone under low temperatures," Journal of China Coal Society, vol. 43, no. 4, pp. 967-975, 2018.

[29] W. Q. Zhang, C. M. Mu, and C. Q. Li, "Study on dynamic mechanical properties of coal under impact loading," Coal Science and Technology, vol. 47, no. 10, pp. 198-204, 2019.

[30] F. Zou, Z. F. Fang, and M. Y. Xia, "Study on dynamic mechanical properties of limestone under uniaxial impact compressive loads," Mathematical Problems in Engineering, vol. 2016, Article ID 5207457, 11 pages, 2016. 